\title{
Is there a relationship between symptoms of the irritable bowel syndrome and objective measurements of large bowel function? A longitudinal study
}

\author{
G J OETTLÉ AND K W HEATON \\ From the University Department of Medicine, Bristol Royal Infirmary, Bristol
}

SUMMARY Four patients with the irritable bowel syndrome completed 28 day continuous stool collections and concurrent symptom diaries. The diaries revealed that three patients had multiple pains. When the diaries were compared with objective measurements, no relationship could be detected between the occurrence of pain or any other symptom on the one hand and stool weight, stool form or consistency, mean whole gut transit time, or interdefecatory transit on the other. Patients' descriptions of urgency, looseness and frequency of defecation give little guide to intestinal events, at least using currently available techniques.

The diagnosis of the irritable bowel syndrome (IBS) is based largely on symptoms of altered bowel habit. There are few reports of patients' stool weight and transit time, however, and the published studies have been done over short periods - most less than three days, none more than five days. Some have shown complaints of diarrhoea and constipation to correlate with objective measurements of bowel function ${ }^{1-4}$ but others have not. ${ }^{-57}$ No long term studies have been reported. This could be important because colonic function is very variable in normal people. ${ }^{8}$

The abdominal pain of IBS is generally blamed on spasm of the intestinal smooth muscle but some attribute it to undue sensitivity of parts of the gut..$^{211}$ There is similar doubt about the origin of the symptom of bloating or abdominal distension. If pain and bloating are caused by altered gut motility, then their onset and disappearance might be associated with changes in bowel function. The aim of this study was to determine whether such relationships exist by making prolonged observations of bowel function in IBS patients who simultaneously kept a detailed diary of their symptoms and bowel habit.

Address for correspondence: Dr K W Heaton, Dept of Medicine, Bristol Royal Infirmary, Bristol BS2 8HW.

Received for publication 13 June 1986

\section{Methods}

PATIENTS

Thirty outpatients with irritable bowel syndrome were considered for this study. Only four met all our selection criteria, however (intelligence, motivation, cooperativeness, and residence within $10 \mathrm{~km}$ of the centre of Bristol, as well as a lifestyle which permitted collection of every stool without social disruption or inconvenience) and were willing to participate. Clinical details are given in Table 1. All patients had been investigated by standard means: history, examination, faecal occult blood, sigmoidoscopy, white cell count, haemoglobin, and viscosity; also barium enema and other investigations as appropriate. The patients ate ad libitum during the study. The study was planned (for the women) to overlap one menstrual period.

Patients kept a diary of symptoms and bowel actions for the entire 28 days of the study. For each bowel action its time was recorded, also - using a multiple-choice form - the consistency of the stool ('loose', 'normal' or 'hard') and whether or not defecation was associated with urgency, mucus, pain relief or straining. For each episode of pain, patients noted its site, severity, quality, duration, and relieving factors. Episodes of distension ('bloating') and increased flatus were also recorded. 
Table 1 Patient characteristics and symptoms (on history)

\begin{tabular}{|c|c|c|c|c|c|c|c|c|c|c|c|}
\hline & Age & Sex & $\begin{array}{l}\text { Duration } \\
\text { of } \\
\text { symptoms } \\
\text { (months) }\end{array}$ & Pain & $\begin{array}{l}\text { Alternating } \\
\text { bowel } \\
\text { habit }\end{array}$ & $\begin{array}{l}\text { Painful } \\
\text { constipation }\end{array}$ & $\begin{array}{l}\text { Painless } \\
\text { diarrhoea }\end{array}$ & Mucus & Distension & $\begin{array}{l}\text { Rectal } \\
\text { dissatis- } \\
\text { faction }\end{array}$ & $\begin{array}{l}\text { Pain } \\
\text { relieved } \\
\text { by } \\
\text { defecation }\end{array}$ \\
\hline 1 & 39 & $\mathbf{F}$ & 12 & + & - & + & - & - & + & + & - \\
\hline 2 & 31 & $\mathbf{F}$ & 4 & + & + & - & - & - & + & - & - \\
\hline 3 & 46 & $\mathbf{F}$ & 6 & + & + & - & - & - & - & - & + \\
\hline 4 & 51 & $\mathbf{M}$ & 24 & + & + & - & - & + & + & + & - \\
\hline
\end{tabular}

Mean whole gut transit time (MTT-C) ${ }^{12}$ was measured continuously throughout the 28 days. Fifteen radio-opaque markers were swallowed daily, one capsule containing five markers with each meal. The subjects recorded the time at which they took each capsule, and whether or not they missed a dose. Each week we checked the number of markers consumed.

Every stool passed was collected, using a system of double plastic bags which could be sealed. One of us (GJO) visited the patients' homes at frequent intervals, usually on alternate days, to pick up the bags. Each stool was weighed, graded visually on the Guildford stool form scale ${ }^{13}$ (Table 2) and radiographed so that the markers could be counted. From these counts the size of the marker pool - that is, the numbers of markers retained in the gut, was calculated and, hence, a daily figure for mean transit time (MTT-C). Five day moving averages and interdefecatory transit were also calculated. Interdefecatory transit is an attempt to identify short term changes in colonic transit rate in subjects who defecate more than once in 24 hours. It is defined as the mean interdefecatory marker pool divided by the marker ingestion rate. This pool is obtained by averaging the estimated number of markers in the colon before and after each bowel action, referred to the preceding interdefecatory period, thus:

$\mathrm{IDT}=\left(\mathrm{MP}_{\mathrm{pd}}-\mathrm{N}_{\mathrm{s}} / 2\right) \mathrm{MIR}$ where $\mathrm{MP}_{\mathrm{pd}}=$ marker pool size before defecation

$\mathrm{N}_{\mathrm{s}}=$ number of markers passed in that stool

$\mathrm{MIR}=$ marker ingestion rate $(=0.625$ markers $/ \mathrm{h}$ when the dose is five markers three times a day).

Table 2 Stool form scale ${ }^{13}$

\footnotetext{
1 Loose, watery, runny

2 Mushy, flattened surface; definite flow

Mushy, heaped surface

Collapsed; remnants of original shape visible

Snake-like, coiled or cylindrical, with a smooth surface

Cylindrical with superficial cracks

7 Cylindrical with deep cracks

8 Fragmented or segmented; pellets; corrugated formations; button-like
}

Interdefecatory transit follows the MTT-C curve but varies round it as short term changes in colonic transit occur.

For each patient, the subjective records of symptoms and bowel habit were compared day by day with the objective records of individual stool weight, $24 \mathrm{~h}$ faecal output, stool form, number of bowel actions per day, interval between bowel actions, whole gut transit time (MTT-C), change in MTT-C, interdefecatory transit and marker excretion rate.

\section{Results}

Stool collection was $98 \cdot 7 \%$ complete (153/155). One stool was lost by each of two patients; a differently shaped marker was immediately started and the previous ones allowed to wash out, permitting calculation of the number excreted in the missing stool. Overall results are shown in Table 3.

Stool parameters varied widely in all four subjects. With the exception of patient 1 who was severely constipated, the variation was within normal limits, ${ }^{8}$ although patient 4 passed an excessive number of very small stools (less than $15 \mathrm{~g})$. Small stools $(<20 \mathrm{~g})$ associated with urgency were often graded by the patients as 'loose' despite being solid, even scybalous (form 5 to 8 on the Guildford scale).

There was no relationship between any objective measurement and the presence or severity of any symptom, either singly or in combination. The only exception was that, in patients 1 and 2, some pains were relieved by defecation. No consistent relationship emerged between attacks of pain and meals. What became apparent, however, was the multiplicity and variable nature of the pains. Three patients had a number of identifiably distinct pains, although none of them had complained of a series of different pains at the initial interview.

Patient 1 had painful constipation. All her stools were hard (form 7 or 8 ). During the study her transit time began at $160 \mathrm{~h}$, then fell to $74 \mathrm{~h}$, only to rise to $218 \mathrm{~h}$ during the final week. She suffered much from anal pain on defecation. She also had a 'dragging' lower abdominal pain which tended to start just before a bowel action and end with defecation, but 
Table 3 Defecation and transit measurements (mean $+S D$ [range])

\begin{tabular}{|c|c|c|c|c|c|c|}
\hline Patient & $\begin{array}{l}\text { Weights of } \\
\text { individual stools } \\
(\mathrm{g})\end{array}$ & $\begin{array}{l}\text { Daily faecal } \\
\text { output }(g / d)\end{array}$ & $\begin{array}{l}\text { Stool form or } \\
\text { consistency (scale } \\
1-8)\end{array}$ & $\begin{array}{l}\text { Whole-gut transit- } \\
\text { time }(M T T-C)(h)\end{array}$ & $\begin{array}{l}\text { Overall frequency } \\
\text { of bowel actions } \\
\text { action }\left(d^{-I}\right)\end{array}$ & 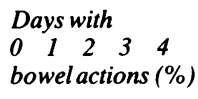 \\
\hline 1 & $57 \pm 36(6-146)$ & $80 \pm 70(0-278)$ & $7 \cdot 9 \pm 0 \cdot 3(7-8)$ & $149 \pm 42(74-218)$ & $1.4 \pm 0.9$ & $173737 \quad 9-$ \\
\hline 2 & $115 \pm 46(60-240)$ & $90 \pm 67(0-240)$ & $7 \cdot 1 \pm 1 \cdot 2(3-8)$ & $74 \pm 12(52-99)$ & $0 \cdot 8 \pm 0 \cdot 5$ & $25714--$ \\
\hline 3 & $121 \pm 61(12-238)$ & $121 \pm 68(0-238)$ & $5 \cdot 6 \pm 2 \cdot 0(1-8)$ & $49 \pm 12(32-77)$ & $1 \cdot 0 \pm 0.5$ & $117811--$ \\
\hline 4 & $46 \pm 45(6-172)$ & $104 \pm 69(0-282)$ & $5 \cdot 9 \pm 1 \cdot 7(2-8)$ & $46 \pm 9(33-64)$ & $2 \cdot 3 \pm 0 \cdot 9$ & 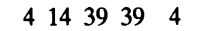 \\
\hline
\end{tabular}

sometimes lasted a few hours for no apparent reason. She also experienced a generalised abdominal malaise. She passed flatus infrequently and only felt bloated once.

Patient 2 was largely pain free; a single episode of pain relieved by defecation during the first week was followed by one day of colicky generalised abdominal pain in the fourth, and, on the final day of the study, a steady dull ache. She was seldom troubled by flatus. Bloating tended to occur on days near days of pain, but with no other obvious pattern. Throughout, her transit time and other parameters varied within normal limits, erring, if anything, in a constipated direction.

Patient 3 started the study with a week of lower abdominal and rectal pain or discomfort, which began about half an hour before a bowel action and ended with it. A pain free week was succeeded by two separate days with a vague, generalised abdominal malaise of variable intensity, starting in the morning and lasting for 24 hours. Flatus passage and bloating were infrequent, and no pattern to their occurrence could be detected. One episode of postprandial pain occurred. During the first week, overall transit was increasing; however, a similar increase in the final week was attended by complete freedom from symptoms.

Patient 4 had a generalised abdominal pain every day which started shortly after breakfast, worsened towards noon and had gone by early evening. He passed a single, bulky stool in the morning and numerous small ones in the early afternoon. These bowel movements had no effect on the pain nor were they prompted by it. Bloated feelings occurred daily. This man's transit time varied between 33 and 64 hours with five 'waves' of faster and slower transit, but neither the absolute values nor the changes showed any relationship with his symptoms.

During menstrual periods, the symptoms continued unabated in patient 1 but patients 2 and 3 were symptom free.

\section{Discussion}

This study has failed to show any temporal relationship between the symptoms of IBS and objective measurements of colonic function, even when transit measurements were manipulated to reveal short term changes. It has long been believed that abnormal motility is the cause of the symptoms in IBS, ${ }^{14}{ }^{15}$ and that pain is caused by hypersegmentation which also tends to delay transit. ${ }^{16-18}$ The present study failed to support these ideas. This may be because all the measurements were 'pan-colonic', providing a summary of overall large bowel function. Local spasm may well not be reflected in overall measurements. It could, perhaps, be revealed by time lapse cineradiography during an attack of pain ${ }^{19}$ or, of course, by measurements of intraluminal pressure, which we did not do.

A limitation of the present findings is that there were only four subjects and the results are not necessarily applicable to all patients with IBS. Nevertheless, our patients seemed to be typical cases of the syndrome. The demanding protocol may well have selected unusually intelligent and obsessional patients. This was inevitable but should not affect the general validity of the findings.

Little attention has been given hitherto to the variability of pain in IBS. With the aid of a diary our patients were easily able to recognise and describe several discomforts. This makes the search for associations between symptoms and objective criteria difficult. Colicky pain, which might plausibly be attributed to local spasm, was rare among our subjects; a diffuse, low grade ache which started gradually and abated slowly, was more common. Its origin is quite obscure.

The lives of many IBS patients are made miserable by rushes of several small motions, often at the most inconvenient times. Subject 4 was an example; daily, he would pass a normal stool in the morning, and then in early afternoon two or three small motions (mostly less than $10 \mathrm{~g}$ ). These were of firm consistency (Guildford 5-7), but he consistently described them as loose. This 'tachyfaecia' is a poorly understood symptom. It may be primarily a problem of rectal control, either learnt, ${ }^{20}$ or inherent. In another study $^{21}$ we have been unable to show any clear radiographic or manometric differences between IBS patients with and without rectal dissatisfaction; but the possibility that rectal dissatisfaction and 
'tachyfaecia' are both due to defective rectal clearing has never been investigated.

It seems reasonable to believe that altered large bowel function underlies at least some of the symptoms of the irritable bowel syndrome; but our understanding of this relationship is rudimentary. Perhaps, in Thompson's phrase, the 'colon moves in ways too subtle and complicated to be accurately assessed by our primitive 'methods'. ${ }^{22}$ Alternatively, it may be that symptoms are due more to heightened sensitivity of the gut or altered perception of large bowel function than to alterations in bowel function itself. A third alternative is that, at least in some patients, abdominal pain ${ }^{23}$ and bloating ${ }^{24}$ may originate in the small intestine.

\section{References}

1 Eastwood MA, Walton BA, Brydon WG, Anderson JR. Faecal weight, constituents, colonic motility, and lactose tolerance in the irritable bowel syndrome. Digestion 1984; 30: 7-12.

2 Cann PA, Read NW, Brown C, Hobson N, Holdsworth $\mathrm{CD}$. Irritable bowel syndrome: relationship of disorders in the transit of a single solid meal to symptom patterns. Gut 1983; 24: 405-11.

3 Cann PA, Read NW, Holdsworth CD. What is the benefit of coarse wheat bran in patients with irritable bowel syndrome? Gut 1984; 25: 168-73.

4 Taylor I, Darby C, Hammond P. Comparison of rectosigmoid myoelectrical activity in the irritable colon syndrome during relapses and remissions. Gut 1978; 19: 923-9.

5 Preston DM, Lennard-Jones JE. Does failure of bisacodyl-induced colonic peristalsis indicate intrinsic nerve damage? [Abstract] Gut 1982; 23: A891.

6 Hillman LC, Stace NH, Pomare EW. Irritable bowel patients and their long-term response to a high-fibre diet. Am J Gastroenterol 1984; 79: 1-7.

7 Hillman LC, Stace NH, Fisher A, Pomare EW. Dietary intakes and stool characteristics of patients with the irritable bowel syndrome. Am J Clin Nutr 1982; 36: 626-9.

8 Wyman JB, Heaton KW, Manning AP, Wicks ACB. Variability of colon function in healthy subjects. Gut 1978; 19: 146-50.
9 Ritchie J. Pain from distension of the pelvic colon by inflating a balloon in the irritable bowel syndrome. Gut 1973; 14: 125-32.

10 Moriarty KJ, Dawson AM. Functional abdominal pain: further evidence that whole gut is affected. $\mathrm{Br} \mathrm{Med} \mathrm{J}$ 1982; 284: 1670-2.

11 Kingham JGC, Dawson AM. Origin of chronic right upper quadrant pain. Gut 1985; 26: 783-8.

12 Cummings JH, Jenkins DJA, Wiggins HS. Measurement of the mean transit time of dietary residue through the human gut. Gut 1976; 17: 210-8.

13 Davies GJ, Crowder M, Reid B, Dickerson JWT. Bowel function measurements of individuals with different eating patterns. Gut 1986; 27: 164-9.

14 Adler HF, Atkinson AJ, Ivy AC. A study of the motility of the human colon: an explanation of dysynergia of the colon, or of the 'unstable colon'. Am J Dig Dis 1941; 8: 197-202.

15 Posey EL, Bargen JA. Observations of normal and abnormal human intestinal motor function. $\mathrm{Am} \mathrm{J} \mathrm{Med}$ Sci 1951; 221: 10-20.

16 Misiewicz JJ. Motility. In: Sircus W, Smith AN, eds. Scientific foundations of gastroenterology. London: Heinemann, 1980: 483-91.

17 Connell AM, Avery-Jones F, Rowlands EN. Motility of the pelvic colon. IV. Abdominal pain associated with colonic hypermotility after meals. Gut 1965; 6: 105-12.

18 Barclay AE. Direct X-ray cinematography with a preliminary note on the nature of non-propulsive movements of the large intestine. Br J Radiol 1935; 8: 652-8.

19 Ritchie J. Mechanisms of pain in the irritable bowel syndrome. In: Read NW, ed. Irritable bowel syndrome. London: Grune \& Stratton, 1985: 163-71.

20 Latimer PR, Campbell D, Latimer MR, Sarna SK, Daniel EE, Waterfall WE. Colonic motility in the irritable bowel syndrome. Gastroenterology 1979; 76: 1181.

21 Oettle GJ, Heaton KW. "Rectal dissatisfaction" in the irritable bowel syndrome. A manometric and radiological study. Int J Colorect Dis 1986; 1: 183-5.

22 Thompson WG. The irritable bowel. Gut 1984; 25: 305-20.

23 Kumar D, Wingate D. The irritable bowel syndrome: a paroxysmal motor disorder. Lancet 1985; ii: 973-7.

24 Trotman IF, Price CC. Bloated irritable bowel syndrome defined by dynamic ${ }^{\%} \mathrm{~T}$ Tc bran scan. Lancet 1986; ii: 364-6. 